\title{
LABCOG: the case of the Interpretative Membrane concept
}

\author{
L. Landau ${ }^{1}$, J. W. Garcia ${ }^{2}$ \& F. P. Miranda ${ }^{3}$ \\ ${ }^{I}$ Department of Civil Engineering, Federal University of Rio de Janeiro, \\ Brazil \\ ${ }^{2}$ Noosfera Projetos Especiais, Brazil \\ ${ }^{3}$ Petrobras Research \& Development Center (CENPES), Brazil
}

\begin{abstract}
The Interpretative Membrane concept is a matrix for XXI Century Architecture, because it translates into a paradigm change, not only in architectural concepts but also in the construction processes. Thus, natural environmental actions and those by which human beings "protect" themselves become understood in an interpretative and adaptive relationship. This covering or "skin" is capable of not just protecting, but using forces such as energy to offer more comfortable use for human life and an environmental balance. The LABCOG project was conceived based on environmental and functional constraints where the design sets itself up to meet the needs demanded by the scientific activities that will be performed there. As such, defragmented and dynamic volumetrics arise that explore several angles to optimize the projections and inclinations necessary for eco-efficiency.

Keywords: interpretative membrane, $L A B C O G$, ecodesign, evolutionary design, virtual reality.
\end{abstract}

\section{Introduction}

At the end of XX Century, two factors stood out with regards to the development of contemporary architecture. The first was the use of computational technologies in architectural drawing and the second was a strong demand in relation to environmental issues. It is exactly at the crossing point of these two factors that arises the concept of an interpretative membrane, to which we dedicate this article. With the objective of presenting such a concept, we will 
examine the case of the "Integrated Laboratory of Basic and Applied Research in Computational Systems and Virtual Reality" (known as LABCOG). This is situated in the Technological Park of the Rio de Janeiro Federal University (UFRJ). We opted to examine the "LABCOG" case because this construction is the fruit of an architectural project that has already been elaborated according to the technological and ecological principles mentioned in this article. As will be seen in this case study, these principles converge in what is called ecodesign.

Another point that must be emphasized, in addition to the two factors mentioned above, is the architect's role. This has been so altered by technological intervention that, without it, projects such as LABCOG would not have been achievable, neither from the architect cognitive elaboration point of view nor from that of the actual construction. Actually, these projects would be impossible as "idea/creations" and "practice/constructions". Today it seems that the intelligent software used in architecture and design act like the architect's real mind and inventive capacity extensions. Moreover, the techno-scientific advances achieved at the turn of this century ended up furnishing civil construction with a series of materials and constructive processes that facilitates the incorporation of ideas elaborated by the architect's inventiveness. This inventiveness evermore mediated by algorithms created in computational environments powered by high performance machines. For this reason technology can be considered as the architect's creative process co-author.

\section{The interpretative membrane concept in architecture}

The interpretative membrane concept (applied to architecture) can be synthesized in the elaboration of an architectural space that is able to intelligently react not only to external factors (or environmental) but also internal factors (such as man's relationship with that space). In the case limit (this is, where our intentions are directed), the idea is that such reactions are intelligent because the architectural unit stores in its memory passed experiences, in a way to change its future behavior. Therefore, this would be an intelligent machine, in the sense that it can learn from experience and act according to such learning. When we talk of "act", what we have in mind is the action of something that "covers" the architectural unit, just like a membrane covers a cell. It is this coverage that will make it possible to change the unit form according to the readings made by its sensors over time.

It only remains to emphasize still that the core of this membrane concept is the interpretation notion. By the same token, such a notion bases itself on the verification that it is already currently possible, thanks to artificial intelligence, conceive and build an architectural space or a construction that can interpret data originating not only from the outer environment but also derived from its interior. This would be an architecture that would react and would dialog with these variables (whether they were human or non-human). 


\section{LABCOG: the membrane concept as an approach to the ecodesign notion}

In this context, LABCOG was conceived for the purpose of formalizing the first steps of the interpretative membrane idea, since its project was based on the possibilities opened up by architectural technological advances and changes in the level of the ecological conscience that characterized the beginning of the XXI century. To be precise, although LABCOG approaches preliminary aspects of the interpretative membrane idea, we believe that this construction already can be considered as a kind of "state of the art" of this concept. With the outcome, the very elaboration of the project itself incorporated a reading of environmental factors, in other words, this project was intelligently drawn with reactions to the environmental variables incorporated in its own form.

Therefore, for example, the notion of ecodesign being present in LABCOG cannot be understood as a mere metaphor of natural forms, in other words, like structures elaborated by humans that just mimic those created by natural evolution. In LABCOG, we did not try to copy specific natural forms that are evolutionary products, but we tried to reproduce its own intelligence that presides over the evolutionary processes.

In this sense, we understand the studies concerning the interpretative membrane concept, as well as its applications in the architecture field, can contribute to form a new approach to ecodesign. The description of the LABCOG architectural project will follow made in the light of these considerations.

\section{The design program $\mathrm{LABCOG}$}

The main objective of the building is to house the CAVE (Cave Automatic Virtual Environment) of the Laboratory for Engineering Computational Methods in COPPE/UFRJ (Figure 1), in addition to research rooms, a library, the multimedia room and workrooms to accommodate researchers. Therefore, the project was prepared in order to meet the demand for an attractive advanced virtual reality space like a big "media center".

As mentioned, the adopted program is based on the idea of a building that arises from environmental and functional constraints. Thus defragmented and dynamic volumetrics emerge, which explore various ways to optimize not only the projections but also the slopes required for an eco-efficient building. This justifies the absence of orthogonal planes.

\section{Studies using Evolutionary Design}

The following diagram in Figure 2 seek to explain how we used Evolutionary Design, which is a software that uses algorithms to draw geometric shapes during a time series, being refined into a kind of evolutionary process. 


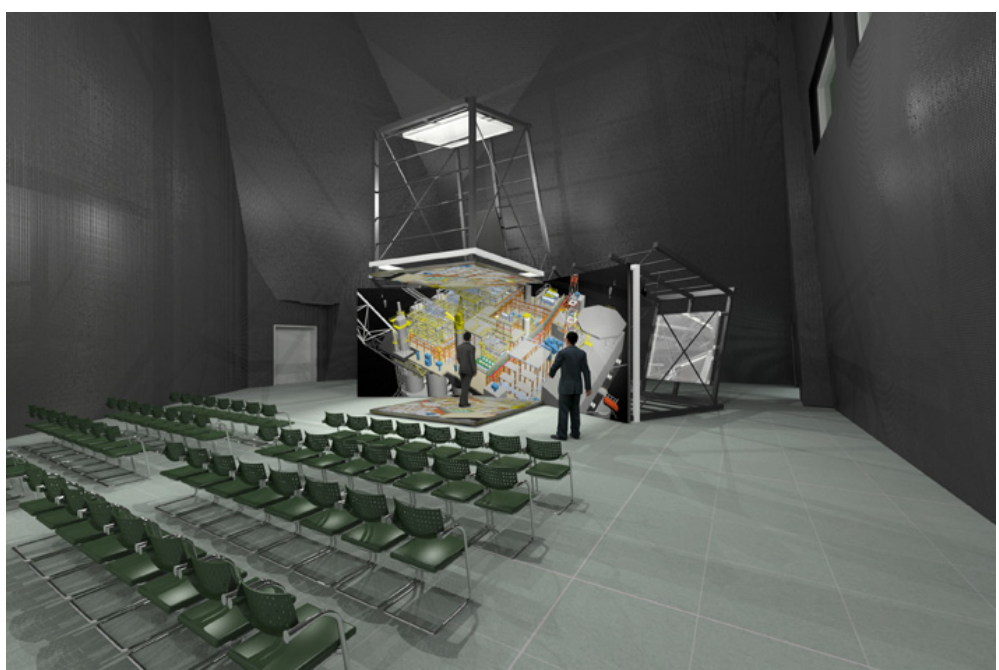

Figure 1: $\quad$ Cave Automatic Virtual Environment (CAVE).

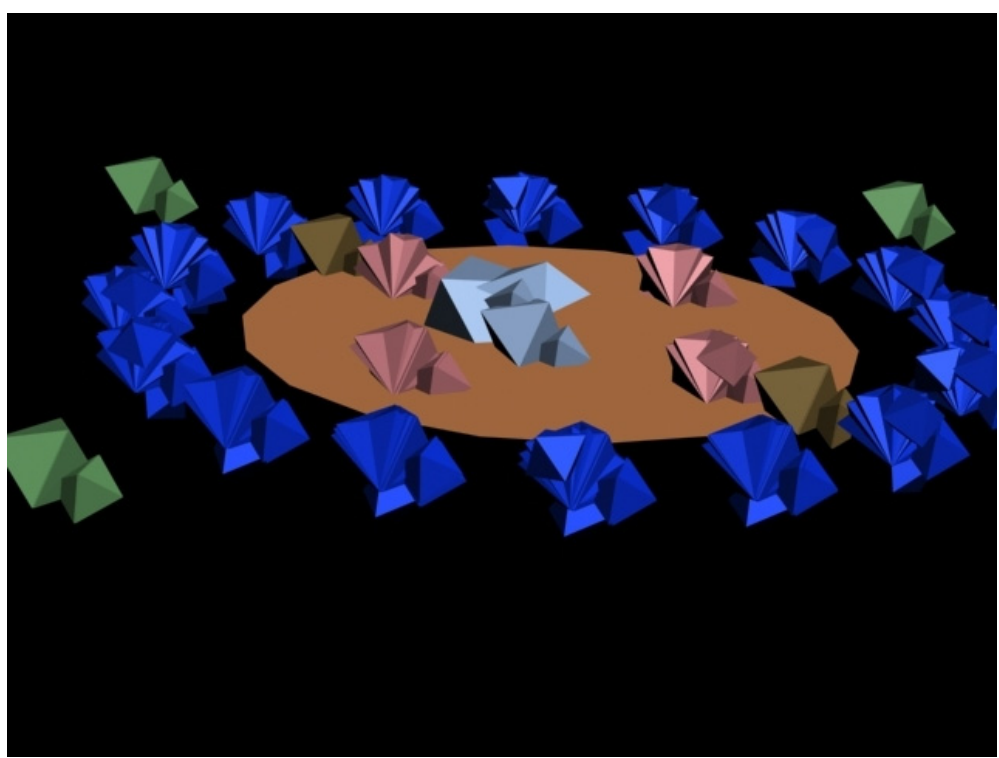

Figure 2: Results of the evolutionary design studies. 
The emergence from environmental and functional constraints is through an intensive dialogue with all the actors involved in LABCOG. It is this dialogue that leads to the idea of the membrane. As an example of this pioneering idea, the architecture of the laboratory aims to establish a new coexistence between human society and high-performance, increasingly intelligent and dynamic computers. Furthermore, the intention is to establish mediation with a sustainable environment, historically regarded as an enemy to be controlled. In this sense, the project was designed not to dominate, but to build a conducive dialogue with climatic conditions such as rain, wind and temperature, whose behavior has varied because of climate change. This proposal is a challenge to the XXI Century, as it calls for the construction of a new epistemology, where the laws governing the creation of forms produced by nature are invited to dialogue with the cognitive processes of the architect.

We want neither ready made answers nor forms: what is sought here is the way (natural) to obtain forms through a dialogue mediated by intelligence, which criticizes the metaphorized ecodesign (Figures 3, 4 and 5). In this case, the ecodesign dialogue made of responses to nature. Natural forms are not imitated or mimicked, because in truth, the membrane functions as a semiotic machine $[1,2]$.

In LABCOG the first steps toward this notion of interpretative membrane were made. In this sense, the project sought to build upon the environmental constraints in favor of a sustainable, functional and aesthetically innovative architecture, which is remarkable for its glass and irregular structure, like a cut gem (Figures 7, 8 and 9). A key feature of the laboratory is the quality of the

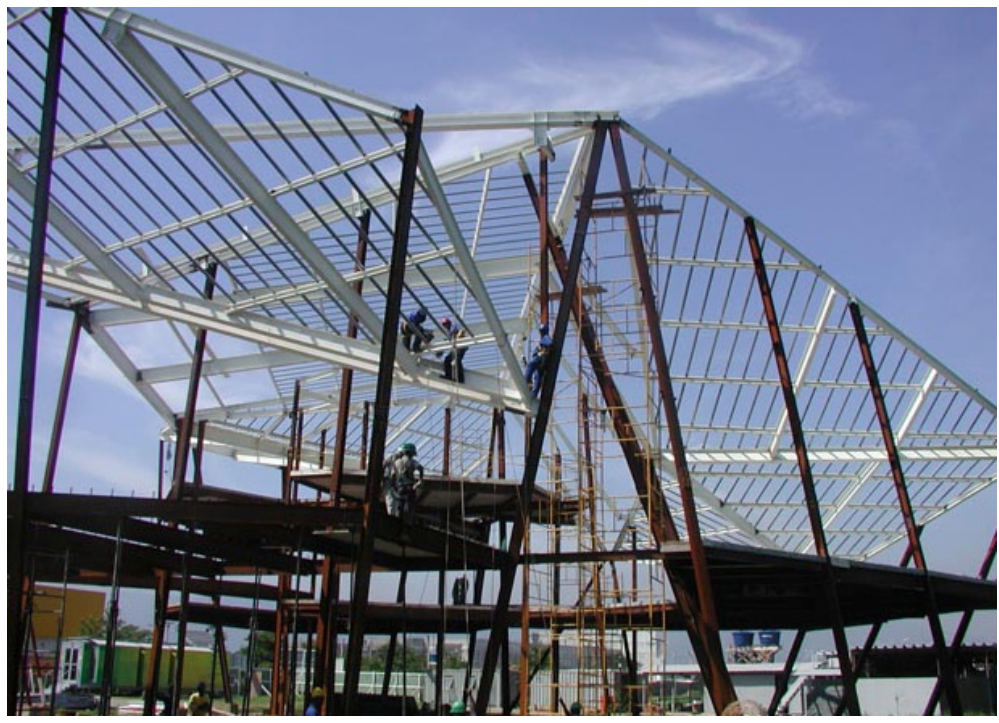

Figure 3: The construction (steel structure). 


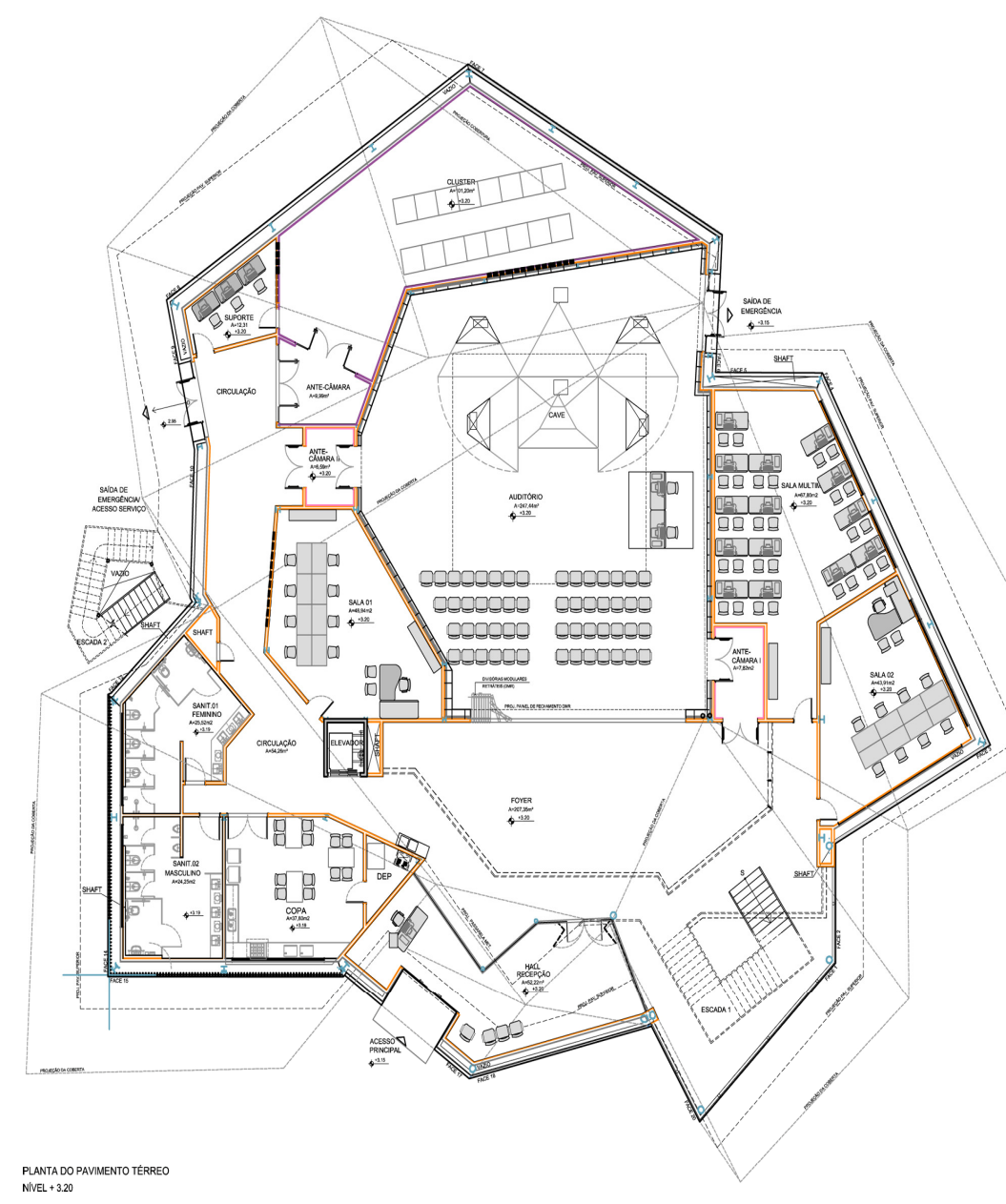

Figure 4: The ground floor plan. 


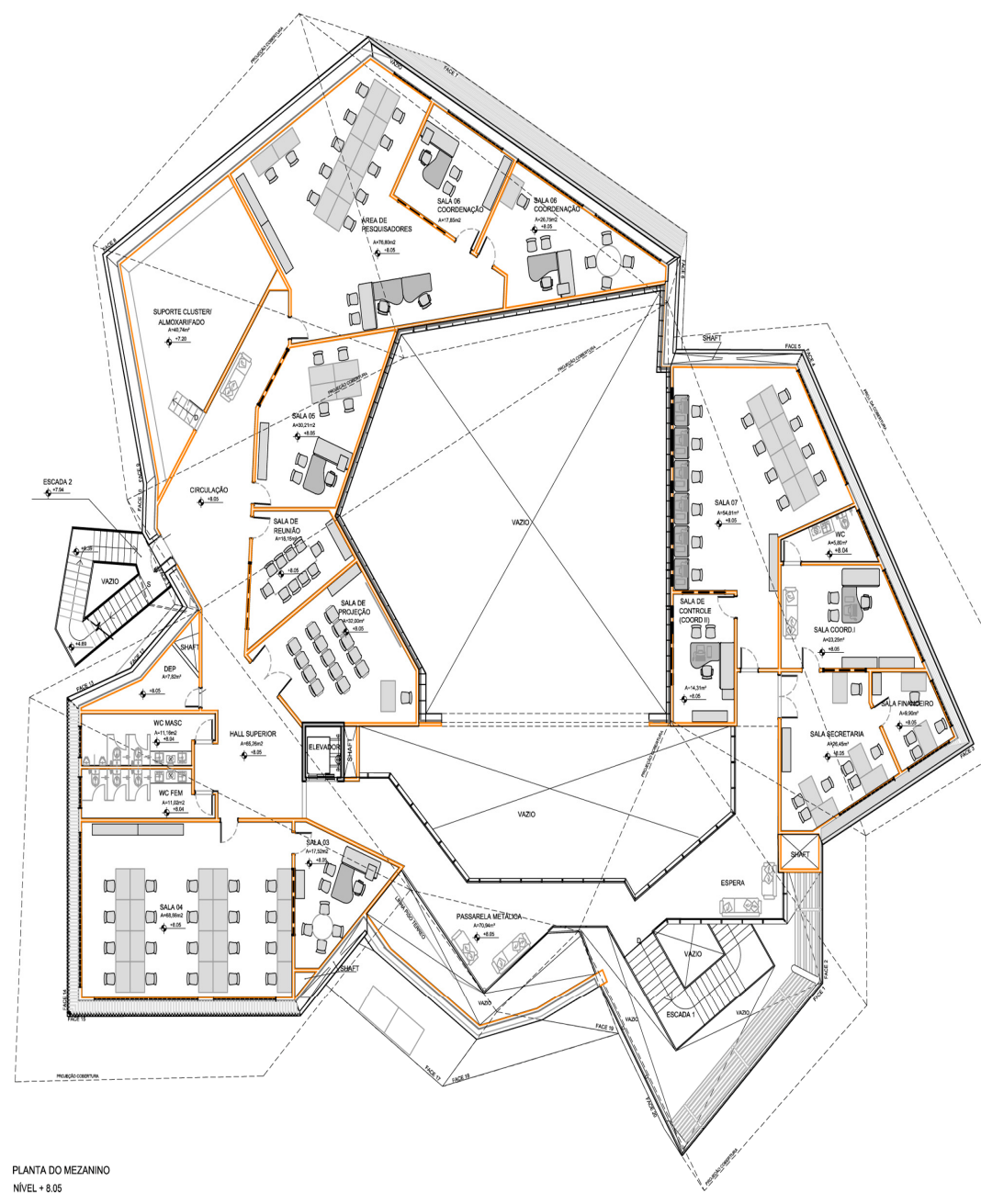

Figure 5: The mezzanine floor plan. 


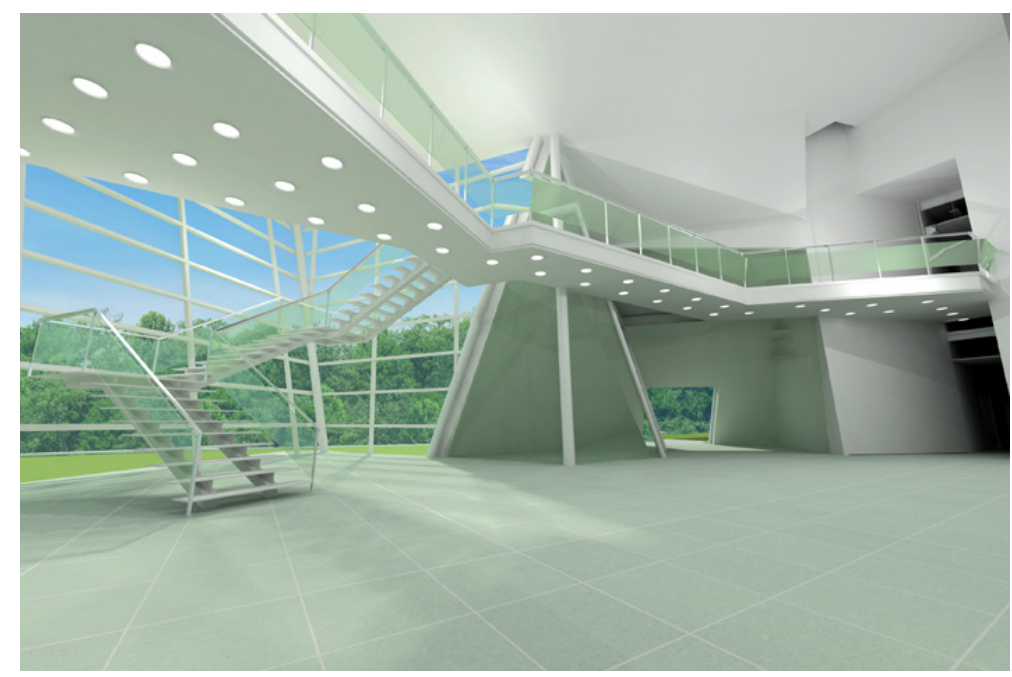

Figure 6: Digital model of the internal space.

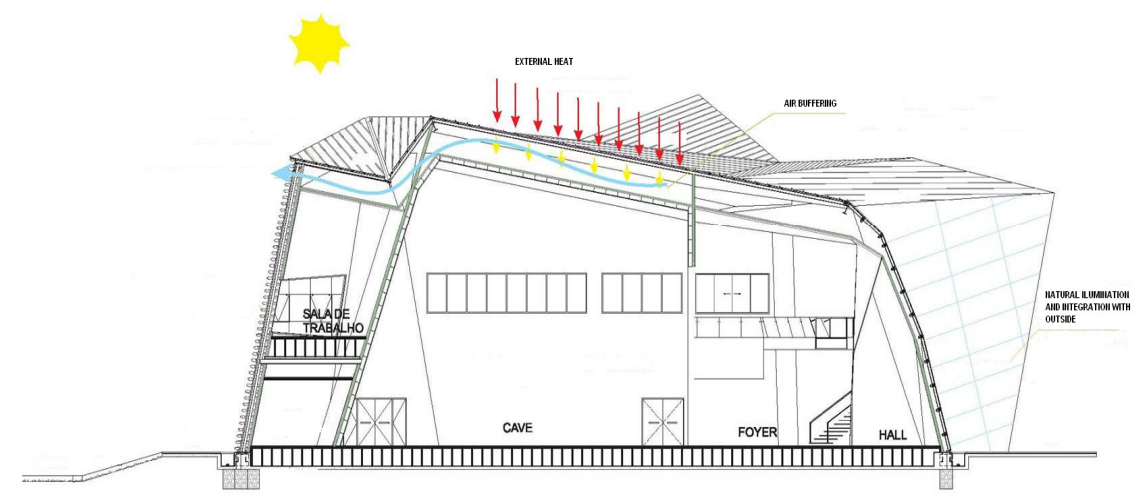

Figure 7: Diagram concept of membrane. 


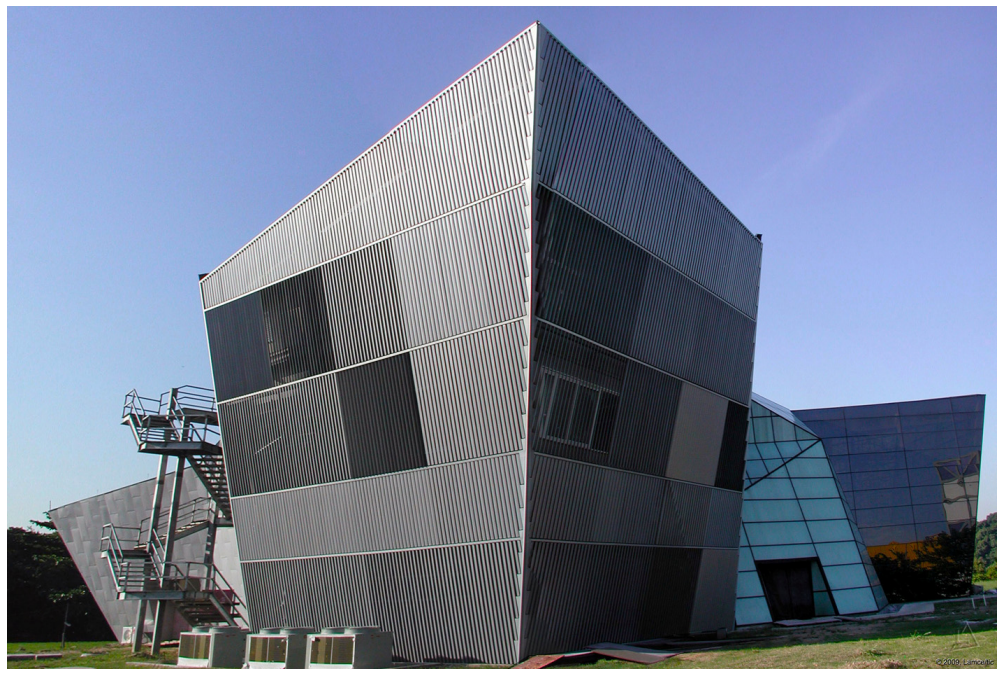

Figure 8: $\quad$ Photograph of the LABCOG perspective.

internal environment by creating spaces that go beyond the usual sound and thermal comfort, an atmosphere conducive to innovation and the work of collective creation, with emphasis on common areas marked by the continuity of the building (Figure 6).

\section{Conclusions}

The Integrated Laboratory of Applied and Basic Research in Computer Systems and Virtual Reality (LABCOG) is situated in the Technological Park of the Rio de Janeiro Federal University (UFRJ). The project is based on the opportunities offered by technological advances in architecture and changes in the level of ecological consciousness that characterized the beginning of the XXI Century. This convergence suggests the emergence of a new conceptual field, whose epicenter, in architecture, can be designated as "interpretative membrane".

The assumptions involved in this approach are as follows:

(a) Innovation aesthetics, featuring architecture as the enabler for a differentiated experience of spatiality. Architecture conforms to the result of the functional and the natural needs of the dynamics between man and nature.

(b) Inter-relationship between man and nature, enabling the optimization of environmental factors in favor of an "environmentally integrated architecture", where the user and their needs are the parameters used by the ecoefficiency of a configuration of a space in an architectural unit. 


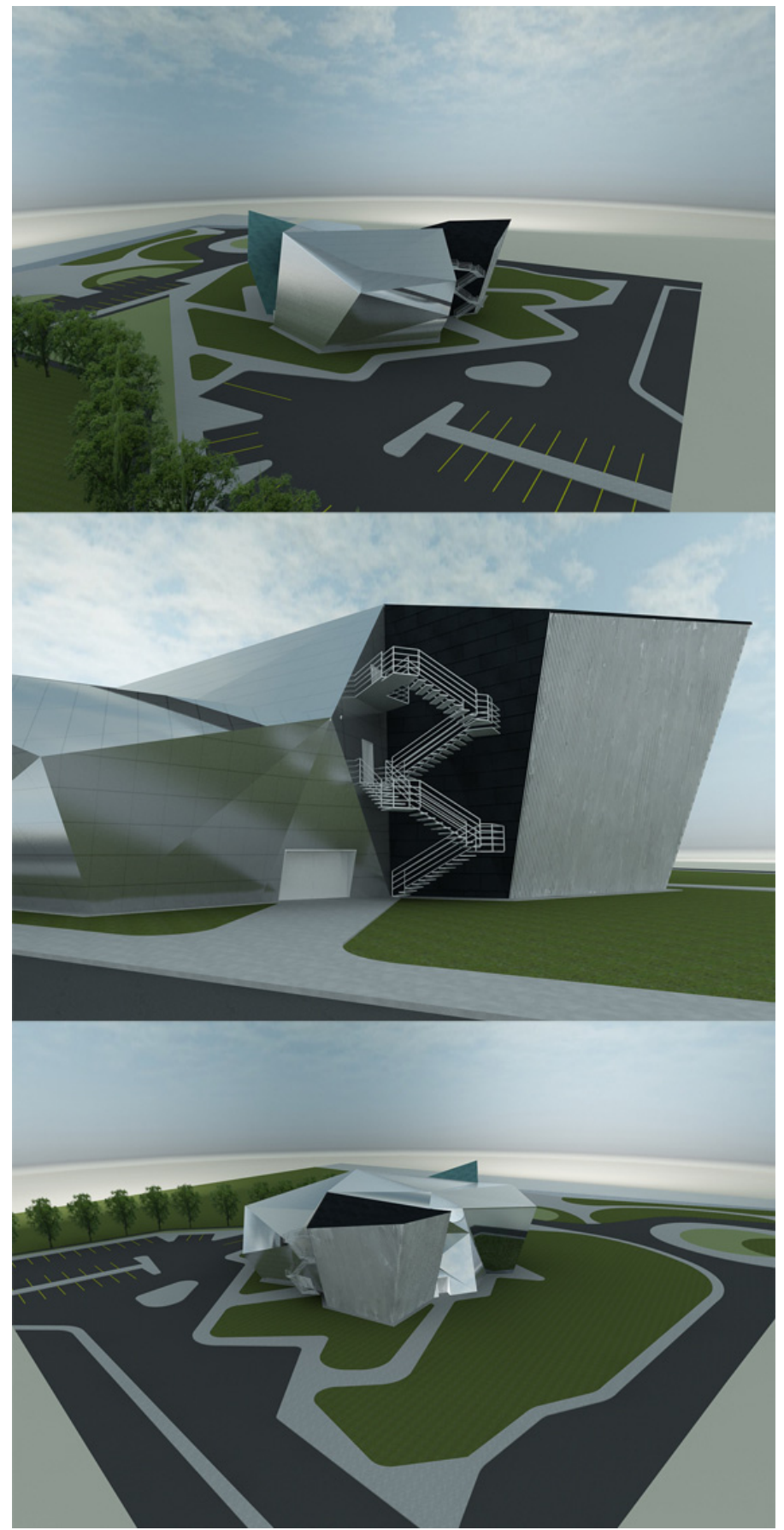

Figure 9: Digital model of the building. 


\section{References}

[1] Charles Sanders Peirce, Christian Kloesel \& Nathan Houser - The Essential Peirce, vol. 1: Selected Philosophical Writings (1867-1893). Indiana University Press. 1992

[2] Antônio Machuco Rosa - O Conceito de Continuidade em Charles S. Peirce. Braga, Gulbenkian, Fundação para Ciência e Tecnologia. 2003. 